\title{
Genome-wide association study of the age of onset of childhood asthma
}

\section{Citation}

Forno, Erick, Jessica Lasky-Su, Blanca Himes, Judie Howrylak, Clare Ramsey, John Brehm, Barbara Klanderman, et al. 2012. Genome-wide association study of the age of onset of childhood asthma. Journal of Allergy and Clinical Immunology 130, no. 1: 83-90.e4. doi:10.1016/ j.jaci.2012.03.020.

\section{Published Version}

doi:10.1016/j.jaci.2012.03.020

\section{Permanent link}

http://nrs.harvard.edu/urn-3:HUL.InstRepos:27003765

\section{Terms of Use}

This article was downloaded from Harvard University's DASH repository, and is made available under the terms and conditions applicable to Other Posted Material, as set forth at http:// nrs.harvard.edu/urn-3:HUL.InstRepos:dash.current.terms-of-use\#LAA

\section{Share Your Story}

The Harvard community has made this article openly available.

Please share how this access benefits you. Submit a story.

\section{Accessibility}


Published in final edited form as:

J Allergy Clin Immunol. 2012 July ; 130(1): 83-90.e4. doi:10.1016/j.jaci.2012.03.020.

\section{Genomewide association study of the age of onset of childhood asthma}

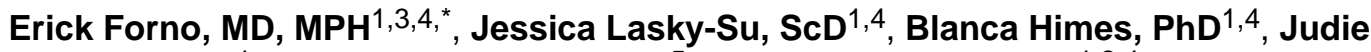
Howrylak, MD ${ }^{1}$, Clare Ramsey, MD, MPH ${ }^{5}$, John Brehm, MD, MPH ${ }^{1,2,4}$, Barbara Klanderman, PhD $^{1}$, John Ziniti, BA ${ }^{1}$, Erik Melén, MD, PhD ${ }^{1,6,7}$, Goran Pershagen, MD, PhD $^{6}$, Magnus Wickman, MD, PhD ${ }^{6,8}$, Fernando Martinez, MD $^{9}$, Dave Mauger, PhD $^{10}$, Christine Sorkness, PharmD ${ }^{11}$, Kelan Tantisira, MD ${ }^{1,2,4}$, Benjamin A. Raby, MD, MPH ${ }^{1,2,4}$, Scott T. Weiss, MD, MS ${ }^{1,4}$, and Juan C. Celedón, MD, DrPH ${ }^{12}$

${ }^{1}$ Channing Laboratory, Brigham and Women's Hospital, Boston, MA

${ }^{2}$ Division of Pulmonary/Critical Care Medicine, Dept. of Medicine, Brigham and Women's Hospital, Boston, MA

${ }^{3}$ Division of Pediatric Pulmonology, Dept. of Pediatrics, University of Miami, Miami, FL

${ }^{4}$ Harvard Medical School, Boston, MA

${ }^{5}$ Dept. of Medicine, University of Manitoba, Winnipeg, Canada

${ }^{6}$ Institute of Environmental Medicine, Karolinska Institutet, Stockholm, Sweden

${ }^{7}$ Astrid Lindgren Children's Hospital, Karolinska University Hospital, Stockholm, Sweden

${ }^{8}$ Sachs Children's Hospital, Stockholm, Sweden

${ }^{9}$ Department of Pediatrics, University of Arizona, Tucson, AZ

${ }^{10}$ Penn State Hershey College of Medicine, Hershey, PA

${ }^{11}$ University of Wisconsin, Madison, WI

${ }^{12}$ Division of Pediatric Pulmonary Medicine, Allergy and Immunology, Dept. of Pediatrics, Children's Hospital of Pittsburgh of UPMC, University of Pittsburgh School of Medicine,

Pittsburgh, PA

\section{Abstract}

BACKGROUND—Childhood asthma is a complex disease with known heritability and phenotypic diversity. Although an earlier onset has been associated with more severe disease, there has been no genome-wide association study of the age of onset of asthma in children.

OBJECTIVE-To identify genetic variants associated with earlier onset of childhood asthma.

\footnotetext{
(C) 2012 American Academy of Allergy, Asthma and Immunology. Published by Mosby, Inc. All rights reserved.

*Corresponding author: Erick Forno, M.D., M.P.H. Department of Pediatrics, University of Miami, 1580 NW $10^{\text {th }}$ Ave \#125, Miami, FL 33136, Phone: 305.243.1420; Fax: 305.243.1262, eforno@med.miami.edu.

Online Supplement: This article has an online data supplement, accessible at http://www.jacionline.org.

Publisher's Disclaimer: This is a PDF file of an unedited manuscript that has been accepted for publication. As a service to our customers we are providing this early version of the manuscript. The manuscript will undergo copyediting, typesetting, and review of the resulting proof before it is published in its final citable form. Please note that during the production process errors may be discovered which could affect the content, and all legal disclaimers that apply to the journal pertain.
} 
METHODS-We conducted the first genome-wide association study (GWAS) of the age of onset of childhood asthma among participants in the Childhood Asthma Management Program (CAMP), and used three independent cohorts from North America, Costa Rica, and Sweden for replication.

RESULTS-Two SNPs were associated with earlier onset of asthma in the combined analysis of CAMP and the replication cohorts: : rs9815663 (Fisher's P value $=2.31 \times 10^{-8}$ ) and rs7927044 $\left(\mathrm{P}=6.54 \times 10^{-9}\right)$. Of these two SNPs, rs9815663 was also significantly associated with earlier asthma onset in an analysis including only the replication cohorts. Ten SNPs in linkage disequilibrium with rs9815663 were also associated with earlier asthma onset $\left(2.24 \times 10^{-7}<\mathrm{P}<\right.$ $8.22 \times 10^{-6}$ ). Having $\geq 1$ risk allele of the two SNPs of interest (rs9815663 and rs7927044) was associated with lower lung function and higher asthma medication use during 4 years of follow-up in CAMP.

CONCLUSIONS-We have identified two SNPs associated with earlier onset of childhood asthma in four independent cohorts.

\section{Keywords}

Asthma; pediatrics; age of onset; asthma genetics; C1orf100; genome-wide association study; pediatric asthma

\section{INTRODUCTION}

Asthma is a complex disease affecting approximately 7 million children in the United States (1). Variants in more than 40 genes have been associated with asthma $(2,3)$. Of these potential asthma susceptibility genes, a handful (e.g., ORMDL3, PDE4D, DENND1B) have been identified by genome-wide association studies (GWAS)(4-7). Recently, a large-scale GWAS confirmed $O R M D L 3$ and identified several other variants, including IL1RL1/ IL18R1, HLA-DQ, IL-33, and SMAD3 (8).

Childhood asthma has significant phenotypic heterogeneity. The age of onset of asthma has important phenotypic and prognostic implications $(9,10)$, and an earlier age of onset is associated with increased severity of asthma in children with symptoms persisting into school age and adolescence $(11,12)$.

In recent years, two studies looking at variants of $O R M D L 3$ found them to be strongly associated with asthma only among those whose symptoms started before $4-5$ years of age $(13,14)$. However, there have been no genome-wide studies directly assessing the genetic determinants of the age of onset of asthma in children. We present the results of a GWAS of the age of onset of asthma in a cohort of North American children enrolled in the Childhood Asthma Management Program (CAMP), followed by replication studies in three independent cohorts of asthmatic children from Latin America, North America, and Europe.

\section{METHODS}

\section{Population for GWAS}

CAMP was a multi-center clinical trial of the effects of anti-inflammatory medications in children with mild to moderate asthma ages 5-12 years at enrollment. Study protocol and subject recruitment have been described in detail $(15,16)$. Of the 1,024 children in CAMP, we included 573 genotyped non-Hispanic white children (413 index children in nuclear families and 160 singletons) in our analysis. Further details can be found in the Online Supplement. CAMP was approved by the Institutional Review Boards of Brigham and Women's Hospital and the other participating centers. 


\section{Replication Cohorts}

GACRS: The protocols for subject recruitment and data collection for the Genetics of Asthma in Costa Rica Study (GACRS) have been previously described $(17,18),(19)$. A total of 591 children (ages 6-14 years) were included in the replication analysis. BAMSE: BAMSE (Children Allergy Milieu Stockholm Epidemiological Survey) is a study of Swedish children recruited at birth between 1994 and 1996 and followed prospectively. BAMSE protocols have been previously described $(20,21)$. A total of 107 genotyped children with physician-diagnosed asthma and persistent wheezing at age 8 years were included in the analysis. PACT: The Pediatric Asthma Controller Trial (PACT) compared the effectiveness of different controller regimens for asthmatic children ages 6-14 years with mild to moderate persistent asthma and documented bronchial reversibility and/or methacholine sensitivity (22). A total of 233 genotyped children were included in the analysis. Data from PACT was available through the Single-nucleotide Polymorphism Health Association Asthma Resource Project (SHARP, see Acknowledgments). All studies (GACRS, BAMSE, and PACT) were approved by the respective Institutional Review Boards and/or Ethics Committees of the participating institutions.

\section{Phenotyping}

The age of onset of asthma was obtained in CAMP, the GACRS, and PACT by parental report via questionnaire at the beginning of each study. The age of onset was analyzed as a continuous variable; any age of onset reported to be less than 6 months of age was considered to be $0.5 \mathrm{yrs}$. In BAMSE, questionnaires were mailed to parents when participating children were approximately ages $1,2,4$, and 8 years. For our analysis, the age of onset was assigned to be the mid point of each time interval: $0.5,1.5,3,5$, or 8 years. Details on phenotyping for other variables can be found in the Online Supplement.

\section{Gene expression}

Gene expression profiling was performed on CD4+ lymphocytes collected from 299 subjects participating in the CAMP Continuation Study, part 2 (CAMPCS/2). Details can be found in the Online Supplement.

\section{Genotyping and quality control}

Genome-wide SNP genotyping was performed by Illumina, Inc. (San Diego, CA) on the HumanHap550v3 BeadChip for CAMP subjects and their parents. After stringent quality control (see Online Supplement) 512,296 SNPs remained for analysis. Genotyping details for replication cohorts can be found in the Online Supplement. When SNPs selected for replication from CAMP were not available in PACT (genotyping done using a different platform), we performed imputation for the original SNPs using data from HapMap and the 1,000 Genome Project (see Online Supplement for details).

\section{Statistical methods}

The population-based GWAS of the age of onset of asthma in CAMP was performed by survival analysis in R via PLINK (23). We used an additive model adjusted for age at enrollment, gender, and environmental tobacco smoke (ETS) exposure during infancy. To correct for population stratification, the main Eigenvectors describing the population substructure as identified by Eigenstrat (24) were included as covariates. We also performed family-based association testing (FBAT, a generalization of the TDT to test association with any phenotype, sampling structure, and pattern of missing marker information) in the 403 index children in nuclear families $(25,26)$. SNPs with the lowest P-values in the populationbased survival analysis that also had FBAT-P $<0.20$ were considered for replication. 
SNPs were tested in GACRS using the same adjusted survival and FBAT analyses, and in BAMSE and PACT using adjusted survival analysis. Replication of the original finding was defined as a nominal 1-sided P-value $<0.05$ with an effect in the same direction as in the GWAS. Fisher combined P-values for all cohorts and for the replication cohorts only were calculated using the population-based P-values from CAMP, BAMSE and PACT, and the FBAT P-value from GACRS (only the P value from the family-based association testing is presented to adjust for potential population stratification, since genome-wide genotypic data to estimate Eigenvectors were not available for this cohort). Bonferroni correction was used as a reference to control for multiple tests; significance threshold was $\mathrm{P}<9.8 \times 10^{-8}$ $(0.05 / 512,296)$ for the GWAS and the analysis of all cohorts, and P < $0.0036(0.05 / 14)$ for the analysis including only the replication cohorts.

\section{RESULTS}

Table 1 summarizes the baseline characteristics of all cohorts. Compared to children in CAMP, those in the GACRS had earlier onset of asthma, higher lung function and eosinophil count, lower total IgE, and were less likely to have been exposed to ETS; children in BAMSE had similar age of onset, lower frequency of exposure to ETS, and higher lung function; and children in PACT were older and had higher lung function, higher frequency of exposure to ETS and lower total IgE.

GWAS P-values are shown in Figure 1. Two SNPs (rs7927044 [chromosome 11q24] and rs10521233 [on 17p12]) were significantly associated with the age of onset of asthma after Bonferroni correction. These two SNPs as well as the 12 SNPs with the next-lowest Pvalues were carried forward for replication in GACRS, BAMSE and PACT.

Three SNPs were significantly associated with asthma onset in at least one of the replication cohorts in the same direction (earlier onset) as in the GWAS (Table 2). SNP rs9815663 (3p26) showed significant association in CAMP BAMSE, and PACT, and a borderline significant association in GACRS ( $\mathrm{P}=0.07)$. SNP rs7927044 (11q24) showed significant association in CAMP and BAMSE. SNP rs4658627 (1q44, within $5 \mathrm{~kb}$ of the gene C1orf100) was significantly associated with an earlier asthma onset in CAMP and the GACRS. After Bonferroni correction, SNPs rs9815663 and rs7927044 were significantly associated (at a genome-wide level) with earlier asthma onset in the combined analysis of all cohorts; rs9815663 was also significant in the combined analysis of the replication cohorts (excluding the GWAS). For rs4658627 the association with earlier asthma onset approached but did not achieve genome-wide statistical significance for all cohorts and for the replication-only combined analyses.

Figure 2 depicts the Kaplan-Meier curves for age of asthma onset in CAMP for these SNPs. For rs9815663, the mean ages of asthma onset in children with 0 (AA), 1 (TA), and 2 (TT) copies of the risk allele were 3.4 (2.6), 2.6 (2.2), and 1.7 (1.8) years, respectively. For rs7927044, children with 0 (TT) and 1 (TA) copies of the risk allele had mean ages of onset of 3.1 (2.5) and 0.8 (0.6) years, respectively; no subjects were homozygous AA. For rs4658627, children with 0 (TT), 1 (TA), and 2 (AA) copies of the risk allele had mean ages of onset of $3.5(\mathrm{SD}=2.8), 2.8(\mathrm{SD}=2.2)$, and $2.6(\mathrm{SD}=2.1)$ years, respectively.

To assess the potential combined effects of the SNPs of interest (rs9815663 and rs7927044) on asthma onset, we conducted an exploratory analysis grouping children from CAMP $(n=573)$ in two strata: those with 0 risk alleles for any of the two SNPs $(n=201)$, and those who had $\geq 1$ risk allele $(n=372)$ (Table 3 and Figure 3). Children with 0 risk alleles had a mean age of onset of 3.4 years $(\mathrm{SD}=2.57)$, while those who had $\geq 1$ risk allele had a mean onset of 2.5 yrs $(\mathrm{SD}=2.13)(\mathrm{P}<0.0001)$. Given the known association between earlier asthma 
onset and increased severity, we tested for association between the SNPs of interest and $\mathrm{FEV}_{1}$, a measure of lung function that is inversely correlated with disease severity. FEV 1 was $\sim 2.8 \%$ lower $(95 \% \mathrm{CI}=0.5-5.2, \mathrm{P}=0.018)$ in children with $\geq 1$ risk alleles than in children without risk alleles. Children with $\geq 1$ risk allele also had a higher mean score for albuterol use than those without risk alleles $(\mathrm{P}=0.004)$; by trial end the difference was $\sim 0.3$ points $(95 \% \mathrm{CI}=0.1-0.5, \mathrm{P}=0.016)$. Results were similar when we excluded children who received budesonide during the CAMP trial (data not shown).

Using imputed genotypic data for CAMP (from the 1000 Genomes Project [1KGP]), we identified 10 nearby SNPs in high LD $\left(r^{2}>0.75\right)$ with SNP rs 9815663 . Figure 4 shows the LD plot and the $-\log 10$ P-values for the associated SNPs. All 10 SNPs were associated with age of onset of asthma in CAMP, with P-values ranging from $8.3 \times 10^{-6}$ to $2.2 \times 10^{-7}$. Three additional SNPs in moderate $\mathrm{LD}\left(\mathrm{r}^{2}=0.5-0.75\right)$ had P-values between $2.0 \times 10^{-4}$ and $5.5 \times 10^{-5}$. There were no SNPs in significant LD with rs4658627 or rs7927044, whether using genotyped or imputed CAMP data (see Figure E2 in the Online Supplement).

We then focused on gene C1orf100, which lies $\sim 5 \mathrm{~Kb}$ from SNP rs4658627, to assess its potential function. In CAMP participants with expression data available from CD4+ T lymphocytes $(\mathrm{n}=227)$, adjusted longitudinal analysis showed that the expression level of C1orf100, while not associated with age of onset of asthma, was associated with lower percent-predicted $\mathrm{FEV}_{1}(\mathrm{P}<0.0001)$ and $\mathrm{FEV}_{1} / \mathrm{FVC}(\mathrm{P}<0.0001)$ throughout the 4 years of the trial. Exploratory analysis including the effects of C1orf100 levels, treatment with budesonide, and an interaction term (C1orf10\%*udesonide) showed a significant interaction between $C 10 r f 100$ expression and budesonide on $\mathrm{FEV}_{1}$ (Table 4), while the interaction was not significant for $\mathrm{FEV}_{1} / \mathrm{FVC}(\mathrm{P}=0.43)$. Expression levels of $C 1$ orf 100 were also associated with an increased risk of severe exacerbations (ER visits, hospitalizations, or prednisone courses for ashma), increased night-time symptom scores, and more missed schooldays for asthma in CAMP (data not shown).

\section{DISCUSSION}

We report the first GWAS of the age of onset of asthma in children and report two SNPs (rs9815663 and rs7927044) significantly associated with an earlier age of onset of asthma in a combined analysis of four cohorts.

Childhood asthma is a complex disease, and our efforts to understand its causes and determinants have been hindered by its phenotypic heterogeneity. It is now recognized that asthma consists of diverse phenotypes, but the definitions of these phenotypes are also variable, depending on the methodologies used and the predictors included in the analysis (27). Nonetheless, the age of onset of symptoms has been consistently identified as an important determinant of the severity of asthma in childhood $(9,11,12,28)$.

The first of the two SNPs we report, rs9815663, located in chromosome 3p26.2, is not in any known gene. However, it was consistently associated with earlier asthma onset in all the cohorts tested (same direction of association and similar effect size), and it met criteria for significance after Bonferroni correction in the CAMP GWAS and in the combined analysis of all cohorts $\left(\mathrm{P}<9.8 \times 10^{-8}\right)$, as well as in the analysis including only the replication cohorts $(\mathrm{P}<0.0036)$. Using imputed data in CAMP, we identified several other SNPs in high and moderate LD with rs9815663 that were also consistently associated with earlier age of asthma onset. The gene closest to this SNP codes for IL-5 receptor alpha (IL5RA). IL-5 plays a role in eosinophil homeostasis and activation (29) and is a potential target for future asthma therapies $(30,31)$; IL5RA is selectively expressed in the bronchial muscle and has been shown to play an eosinophil-independent role in airway hyper-responsiveness (32). 
The second SNP, rs7927044, had the lowest P-value in CAMP, replicated very strongly in BAMSE, and was significantly associated with earlier asthma onset in the combined analysis of all cohorts. However, this SNP did not replicate in the analysis including only the replication cohorts (no significant replication in either the GACRS or in PACT [using the imputed data or an available marker in strong LD with rs7927044 [rs1364780, $\left.\mathrm{r}^{2}=1\right]$ ), likely because of insufficient power (this SNP had low minor allele frequency [1-2\%] in all the cohorts). Given this and the fact that there were no SNPs in significant LD with rs7927044, these results must be cautiously interpreted awaiting follow-up in additional cohorts.

A third SNPs (rs4658267) was not significantly associated with an earlier asthma onset in the combined analysis of all cohorts or in the analysis including only the replication cohorts. However, this SNP had the fourth lowest P value in the analysis of all cohorts and the second lowest $\mathrm{P}$ value in the analysis that included only the replication cohorts. Of interest, SNP rs4658267 is located within $5 \mathrm{~kb}$ of the gene C1orf100 (RefSeq: NM_001012970) on chromosome 1q44 (assembly NCBI36/Hg18, dbSNP build 130). The function of C1orf100 is still unknown, but the analysis of CD4+ T lymphocyte gene expression data showed that higher levels of expression of this gene were associated with lower lung function and other measures of asthma severity in CAMP. Although C1orf100 cannot be confidently identified as a candidate gene for susceptibility to earlier onset of asthma, our genetic expression data for C1orf100 lends significant biological plausibility to SNP rs4658267 and merits follow up. CD4+ T lymphocytes participate in airway inflammation, hyper reactivity, and remodeling, and may be involved in steroid resistance in asthma $(33,34)$.

In this study, children with at least one copy of the risk alleles for an earlier asthma onset had a lower lung function (measured by $\mathrm{FEV}_{1}$ ) and higher reported use of albuterol than those who had no risk alleles. This is consistent with prior results from CAMP, which showed that duration of asthma symptoms was associated with lower lung function, higher symptom scores, and increased use of albuterol (12), as well as with those of epidemiologic studies reporting an association between early asthma onset and increased disease severity in adults (35),(36). Conversely, children with a later age of onset of asthma tend to have a preserved level of lung function at age 6 years when compared to children who have never wheezed (11).

As is likely the case for other complex traits, genetic determinants may interact with environmental and/or pharmacologic factors. While the results of our exploratory analysis need to be interpreted with caution, we report an interaction between CD4+ T lymphocyte expression levels of a gene near one of our SNPs of interest (C1orf100) and treatment with inhaled budesonide on a measure of lung function $\left(\mathrm{FEV}_{1}\right)$ among children in CAMP. To our knowledge, this is the first report of a potential interaction between genetic determinants associated with the age of onset of asthma, lung function later in childhood, and pharmacologic treatment of asthma.

Our study has several limitations. First, we have inadequate power to identify modest genetic effects on asthma onset because of sample size. Second, the age of onset of asthma was ascertained retrospectively via parental report, which may introduce recall bias. Such bias would be non-differential with regard to genotypic data, and thus likely skew our results toward the null hypothesis of no association. Third, due to budgetary constraints, only 14 SNPs among the top-ranked results in our initial cohort were carried forward for replication. However, 2 of these 14 SNPs were also significant in a combined analysis of all cohorts. Clearly a broader search using a larger set of markers is warranted. Fourth, both using genotypic data imputation or high-LD surrogate markers have limitations. 
In summary, we have identified two SNPs associated with earlier age of onset of childhood asthma in a combined analysis of four independent cohorts. We report that having at least one risk allele in any of the two "earlier onset" SNPs is associated with lower lung function and higher medication use during 4 years of follow-up in CAMP. These SNPs may be associated with different disease pathogenesis and/or prognosis. Further studies are needed in this area.

\section{Supplementary Material}

Refer to Web version on PubMed Central for supplementary material.

\section{Acknowledgments}

Sources of support: GACRS is supported by grants HL04370 and HL66289 from the U.S. National Institutes of Health. CAMP is supported by contracts NO1-HR-16044, 16045, 16046, 16047, 16048, 16049, 16050, 16051, and 16052 with the National Heart, Lung and Blood Institute; and General Clinical Research Center grants M01RR00051, M01RR0099718-24, M01RR02719-14, and RR00036 from the National Center for Research Resources. GWAS in BAMSE supported by the European Commission as part of GABRIEL (a multidisciplinary study to identify the genetic and environmental causes of asthma in the European Community) contract number 018996 under the Integrated Program LSH-2004-1.2.5-1, and Wellcome Trust under WT084703MA: “A secondgeneration genome-wide association study for asthma". SHARP genotyping performed by Affymetrix, Inc. under U.S. Federal Government contract number N02-HL-6-4278 from the National Heart, Lung, and Blood Institute.

We thank all the families for their invaluable participation in the GACRS and CAMP studies. We acknowledge the CAMP investigators and research team for their help in data collection. All work on data collected for GACRS was conducted at the Channing Laboratory of the Brigham and Women's Hospital under appropriate policies and human subject's protections.

The BAMSE Study was supported by the Swedish Research Council, Stockholm County Council, Centre for Allergy Research, Karolinska Institutet and the Swedish Heart Lung Foundation. EM is supported by a post doc grant from the Swedish Heart Lung Foundation, the Swedish Fulbright Commission and Riksbankens Jubileumsfond, Erik Rönnberg's scholarship for research on early childhood diseases.

The single-nucleotide polymorphism health association-asthma resource project (SHARP) was funded by the National Heart Lung and Blood Institute, and was composed of researchers from the Asthma Clinical Research Network (ACRN), the Childhood Asthma Management Program (CAMP), and the Childhood Asthma Research and Education (CARE) network.

\section{Abbreviations}

$\begin{array}{ll}\text { 1KGP } & \text { 1000 Genomes Project } \\ \text { BAMSE } & \text { Children Allergy Milieu Stockholm Epidemiological Survey } \\ \text { C1orf100 } & \text { Chromosome 1 open-reading frame 100 } \\ \text { CAMP } & \text { Childhood Asthma Management Program } \\ \text { CI } & \text { Confidence interval } \\ \text { ER } & \text { Emergency room } \\ \text { ETS } & \text { Environmental tobacco smoke } \\ \text { FBAT } & \text { Family-based association testing } \\ \text { FEV1 } & \text { Forced expiratory volume in the first second } \\ \text { GACRS } & \text { Genetics of Asthma in Costa Rica Study } \\ \text { GWAS } & \text { Genome-wide association study } \\ \text { IgE } & \text { Immune globulin E }\end{array}$



IL-5
Interleukin 5
IL5RA
Gene for IL-5 receptor alpha
LD
Linkage disequilibrium
MAF
Minor allele frequency
PACT
Pediatric Asthma Controller Trial
SD
Standard deviation
SHARP
Single-nucleotide Polymorphism Health Association Asthma Resource Project
SNP
Single-nucleotide polymorphism
TDT
Transmission disequilibrium test

\section{References}

1. Moorman JE, Rudd RA, Johnson CA, King M, Minor P, Bailey C, et al. National Surveillance for Asthma --- United States, 1980--2004. Morb Mortal Wkly Rep Surveill Summ. 2007; 56(8):18-54.

2. Ober C, Hoffjan S. Asthma genetics 2006: the long and winding road to gene discovery. Genes Immun. 2006 Mar; 7(2):95-100. [PubMed: 16395390]

3. Weiss ST, Raby BA, Rogers A. Asthma genetics and genomics 2009. Curr Opin Genet Dev. 2009 Jun; 19(3):279-282. [PubMed: 19481925]

4. Moffatt MF, Kabesch M, Liang L, Dixon AL, Strachan D, Heath S, et al. Genetic variants regulating ORMDL3 expression contribute to the risk of childhood asthma. Nature. 2007 Jul 26; 448(7152): 470-473. [PubMed: 17611496]

5. Himes BE, Hunninghake GM, Baurley JW, Rafaels NM, Sleiman P, Strachan DP, et al. Genomewide association analysis identifies PDE4D as an asthma-susceptibility gene. Am J Hum Genet. 2009 May; 84(5):581-593. [PubMed: 19426955]

6. Sleiman PM, Flory J, Imielinski M, Bradfield JP, Annaiah K, Willis-Owen SA, et al. Variants of DENND1B associated with asthma in children. N Engl J Med. 2010 Jan 7; 362(1):36-44. [PubMed: 20032318]

7. Akhabir L, Sandford AJ. Genome-wide association studies for discovery of genes involved in asthma. Respirology. 2011 Apr; 16(3):396-406. [PubMed: 21276132]

8. Moffatt MF, Gut IG, Demenais F, Strachan DP, Bouzigon E, Heath S, et al. A large-scale, consortium-based genomewide association study of asthma. N Engl J Med. 2010 Sep 23; 363(13): 1211-1221. [PubMed: 20860503]

9. Martinez FD, Wright AL, Taussig LM, Holberg CJ, Halonen M, Morgan WJ. Asthma and wheezing in the first six years of life. The Group Health Medical Associates. N Engl J Med. 1995 Jan 19; 332(3):133-138. [PubMed: 7800004]

10. Castro-Rodriguez JA, Holberg CJ, Wright AL, Martinez FD. A clinical index to define risk of asthma in young children with recurrent wheezing. Am J Respir Crit Care Med. 2000 Oct; 162(4 Pt 1):1403-6. [PubMed: 11029352]

11. Taussig LM, Wright AL, Holberg CJ, Halonen M, Morgan WJ, Martinez FD. Tucson Children's Respiratory Study: 1980 to present. J Allergy Clin Immunol. 2003 Apr; 111(4):661-75. quiz 676. [PubMed: 12704342]

12. Zeiger RS, Dawson C, Weiss S. Relationships between duration of asthma and asthma severity among children in the Childhood Asthma Management Program (CAMP). J Allergy Clin Immunol. 1999 Mar; 103(3 Pt 1):376-387. [PubMed: 10069869]

13. Bouzigon E, Corda E, Aschard H, Dizier MH, Boland A, Bousquet J, et al. Effect of 17q21 variants and smoking exposure in early-onset asthma. N Engl J Med. 2008 Nov 6; 359(19):19851994. [PubMed: 18923164] 
14. Halapi E, Gudbjartsson DF, Jonsdottir GM, Bjornsdottir US, Thorleifsson G, Helgadottir H, et al. A sequence variant on $17 \mathrm{q} 21$ is associated with age at onset and severity of asthma. Eur J Hum Genet. 2010 Aug; 18(8):902-908. [PubMed: 20372189]

15. Childhood Asthma Management Program Research Group. The Childhood Asthma Management Program (CAMP): design, rationale, and methods. Control Clin Trials. 1999 Feb; 20(1):91-120. [PubMed: 10027502]

16. The Childhood Asthma Management Program Research Group. Long-term effects of budesonide or nedocromil in children with asthma. N Engl J Med. 2000 Oct 12; 343(15):1054-1063. [PubMed: 11027739]

17. Hunninghake GM, Soto-Quiros ME, Avila L, Ly NP, Liang C, Sylvia JS, et al. Sensitization to Ascaris lumbricoides and severity of childhood asthma in Costa Rica. J Allergy Clin Immunol. 2007 Mar; 119(3):654-61. [PubMed: 17336615]

18. Ly NP, Soto-Quiros ME, Avila L, Hunninghake GM, Raby BA, Laskey D, et al. Paternal asthma, mold exposure, and increased airway responsiveness among children with asthma in costa rica. Chest. 2008 Jan; 133(1):107-14. [PubMed: 17989151]

19. Brehm JM, Celedon JC, Soto-Quiros ME, Avila L, Hunninghake GM, Forno E, et al. Serum vitamin D levels and markers of severity of childhood asthma in Costa Rica. Am J Respir Crit Care Med. 2009 May 1; 179(9):765-771. [PubMed: 19179486]

20. Kull I, Melen E, Alm J, Hallberg J, Svartengren M, van Hage M, et al. Breast-feeding in relation to asthma, lung function, and sensitization in young schoolchildren. J Allergy Clin Immunol. 2010 May; 125(5):1013-1019. [PubMed: 20392479]

21. Melen E, Nyberg F, Lindgren CM, Berglind N, Zucchelli M, Nordling E, et al. Interactions between glutathione S-transferase P1, tumor necrosis factor, and traffic-related air pollution for development of childhood allergic disease. Environ Health Perspect. 2008 Aug; 116(8):10771084. [PubMed: 18709160]

22. Sorkness CA, Lemanske RF Jr, Mauger DT, Boehmer SJ, Chinchilli VM, Martinez FD, et al. Long-term comparison of 3 controller regimens for mild-moderate persistent childhood asthma: the Pediatric Asthma Controller Trial. J Allergy Clin Immunol. 2007 Jan; 119(1):64-72. [PubMed: 17140647]

23. Purcell S, Neale B, Todd-Brown K, Thomas L, Ferreira MA, Bender D, et al. PLINK: a tool set for whole-genome association and population-based linkage analyses. Am J Hum Genet. 2007 Sep; 81(3):559-575. [PubMed: 17701901]

24. Price AL, Patterson NJ, Plenge RM, Weinblatt ME, Shadick NA, Reich D. Principal components analysis corrects for stratification in genome-wide association studies. Nat Genet. 2006 Aug; 38(8):904-909. [PubMed: 16862161]

25. Rabinowitz D, Laird N. A unified approach to adjusting association tests for population admixture with arbitrary pedigree structure and arbitrary missing marker information. Hum Hered. $2000 \mathrm{Jul}-$ Aug;50(4):211-223. [PubMed: 10782012]

26. Van Steen K, Lange C. PBAT: a comprehensive software package for genome-wide association analysis of complex family-based studies. Hum Genomics. 2005 Mar; 2(1):67-69. [PubMed: 15814068]

27. Henderson J, Granell R, Sterne J. The search for new asthma phenotypes. Arch Dis Child. 2009 May; 94(5):333-336. [PubMed: 19147620]

28. Henderson J, Granell R, Heron J, Sherriff A, Simpson A, Woodcock A, et al. Associations of wheezing phenotypes in the first 6 years of life with atopy, lung function and airway responsiveness in mid-childhood. Thorax. 2008 Nov; 63(11):974-980. [PubMed: 18678704]

29. Takatsu K, Kouro T, Nagai Y. Interleukin 5 in the link between the innate and acquired immune response. Adv Immunol. 2009; 101:191-236. [PubMed: 19231596]

30. Flood-Page P, Swenson C, Faiferman I, Matthews J, Williams M, Brannick L, et al. A study to evaluate safety and efficacy of mepolizumab in patients with moderate persistent asthma. Am J Respir Crit Care Med. 2007 Dec 1; 176(11):1062-1071. [PubMed: 17872493]

31. Haldar P, Brightling CE, Hargadon B, Gupta S, Monteiro W, Sousa A, et al. Mepolizumab and exacerbations of refractory eosinophilic asthma. N Engl J Med. 2009 Mar 5; 360(10):973-984. [PubMed: 19264686] 
32. Rizzo CA, Yang R, Greenfeder S, Egan RW, Pauwels RA, Hey JA. The IL-5 receptor on human bronchus selectively primes for hyperresponsiveness. J Allergy Clin Immunol. 2002 Mar; 109(3): 404-409. [PubMed: 11897983]

33. Syed F, Bingham B, Johnson M, Markham AF, Morrison JF. The CD4+ T lymphocyte is a site of steroid resistance in asthma. QJM. 1998 Aug; 91(8):567-572. [PubMed: 9893760]

34. Foster PS, Yang M, Herbert C, Kumar RK. CD4(+) T-lymphocytes regulate airway remodeling and hyper-reactivity in a mouse model of chronic asthma. Lab Invest. 2002 Apr; 82(4):455-462. [PubMed: 11950902]

35. Strachan DP, Griffiths JM, Johnston ID, Anderson HR. Ventilatory function in British adults after asthma or wheezing illness at ages 0-35. Am J Respir Crit Care Med. 1996 Dec; 154(6 Pt 1): 1629-1635. [PubMed: 8970346]

36. Sears MR, Greene JM, Willan AR, Wiecek EM, Taylor DR, Flannery EM, et al. A longitudinal, population-based, cohort study of childhood asthma followed to adulthood. N Engl J Med. 2003 Oct 9; 349(15):1414-1422. [PubMed: 14534334] 


\section{Clinical implications}

Differences in the age of onset in childhood asthma may be associated with different asthma phenotypes, and identifying genes associated with age of onset may have implications for management and prognosis. 


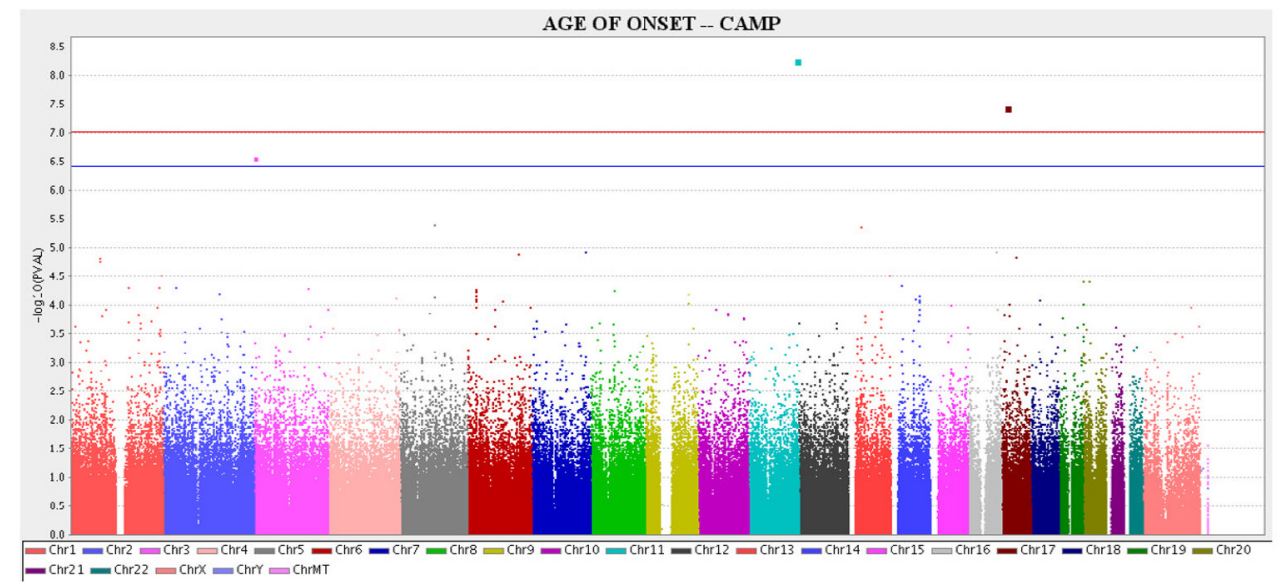

Figure 1. Plots for CAMP GWAS

Manhattan plot shows the $-\log _{10}(\mathrm{P}$-value $)$ by the chromosomal position for the genomewide association analysis with age of onset as the phenotype in the population-based adjusted survival analysis in CAMP.

Red line: Threshold for $\mathrm{P}<0.05$ after Bonferroni correction $\left(\mathrm{P}<9.8 \times 10^{-8}\right)$. Blue line: Threshold for $\mathrm{P}<0.10$ after Bonferroni correction $\left(\mathrm{P}<2.0 \times 10^{-7}\right)$. 

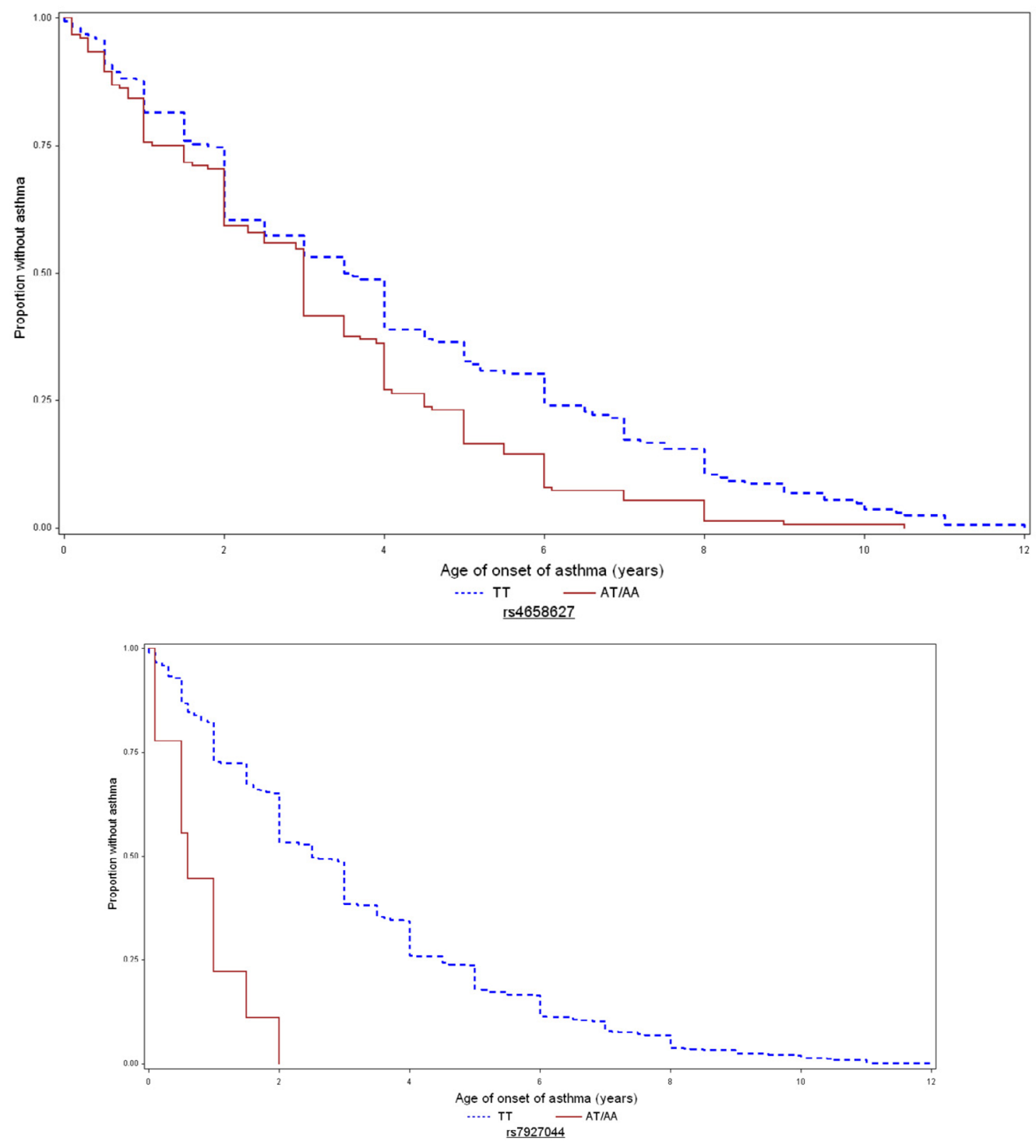


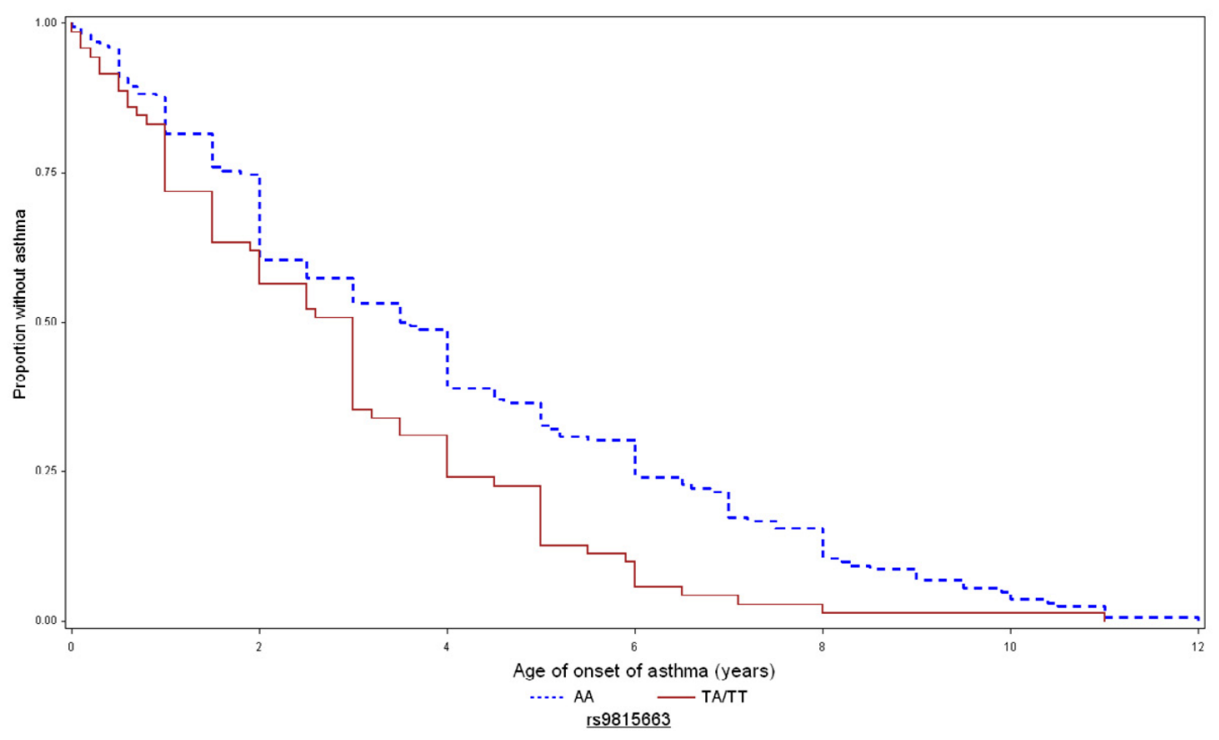

Figure 2. Kaplan-Meier curves for age of onset of asthma in CAMP, by genotype of replicated SNPs

Time to onset of asthma in CAMP for rs9815663 (top), rs7927044 (middle), and rs4658627 (bottom). Blue/dashed line $=0$ risk alleles; red/continuous line $=1-2$ copies of risk allele. 


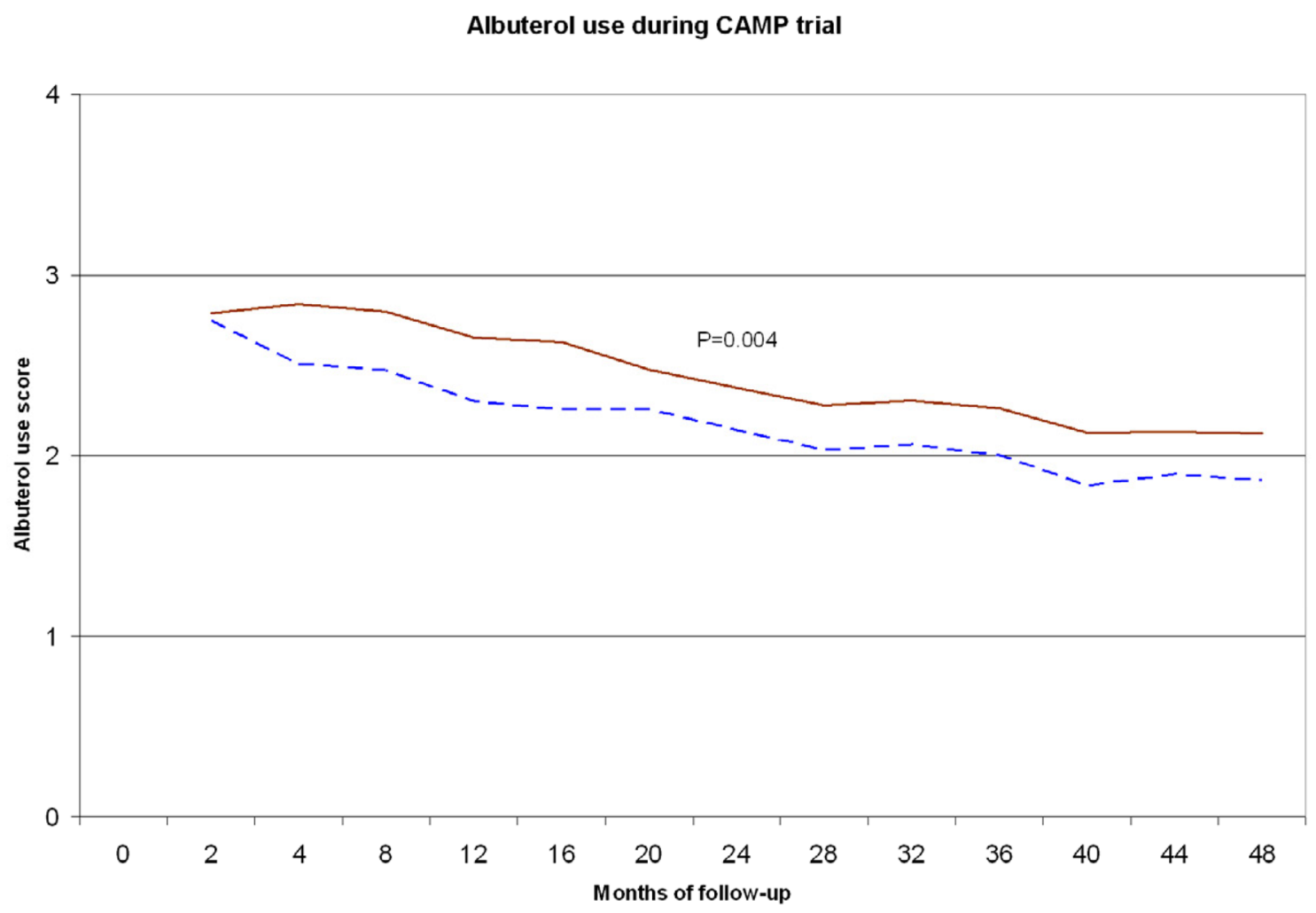

FEV1 during CAMP trial

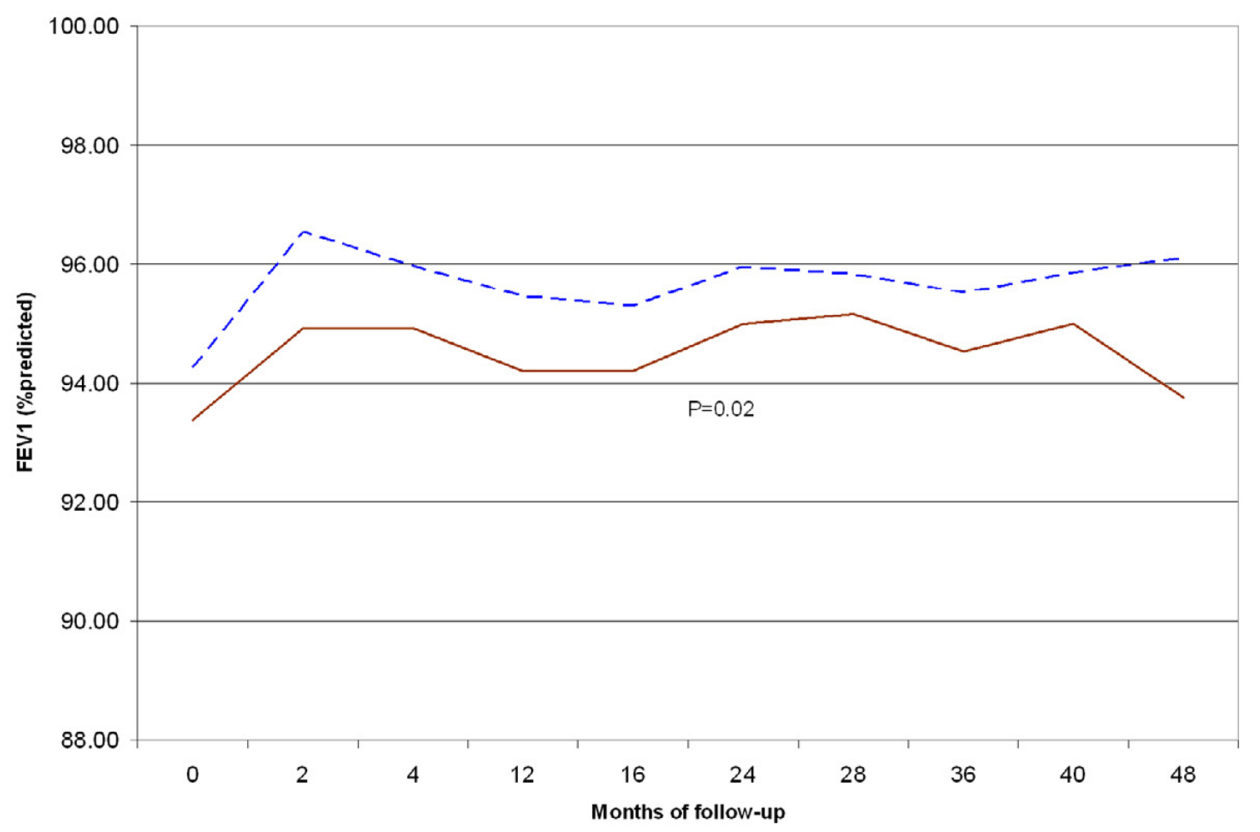

J Allergy Clin Immunol. Author manuscript; available in PMC 2013 July 01. 


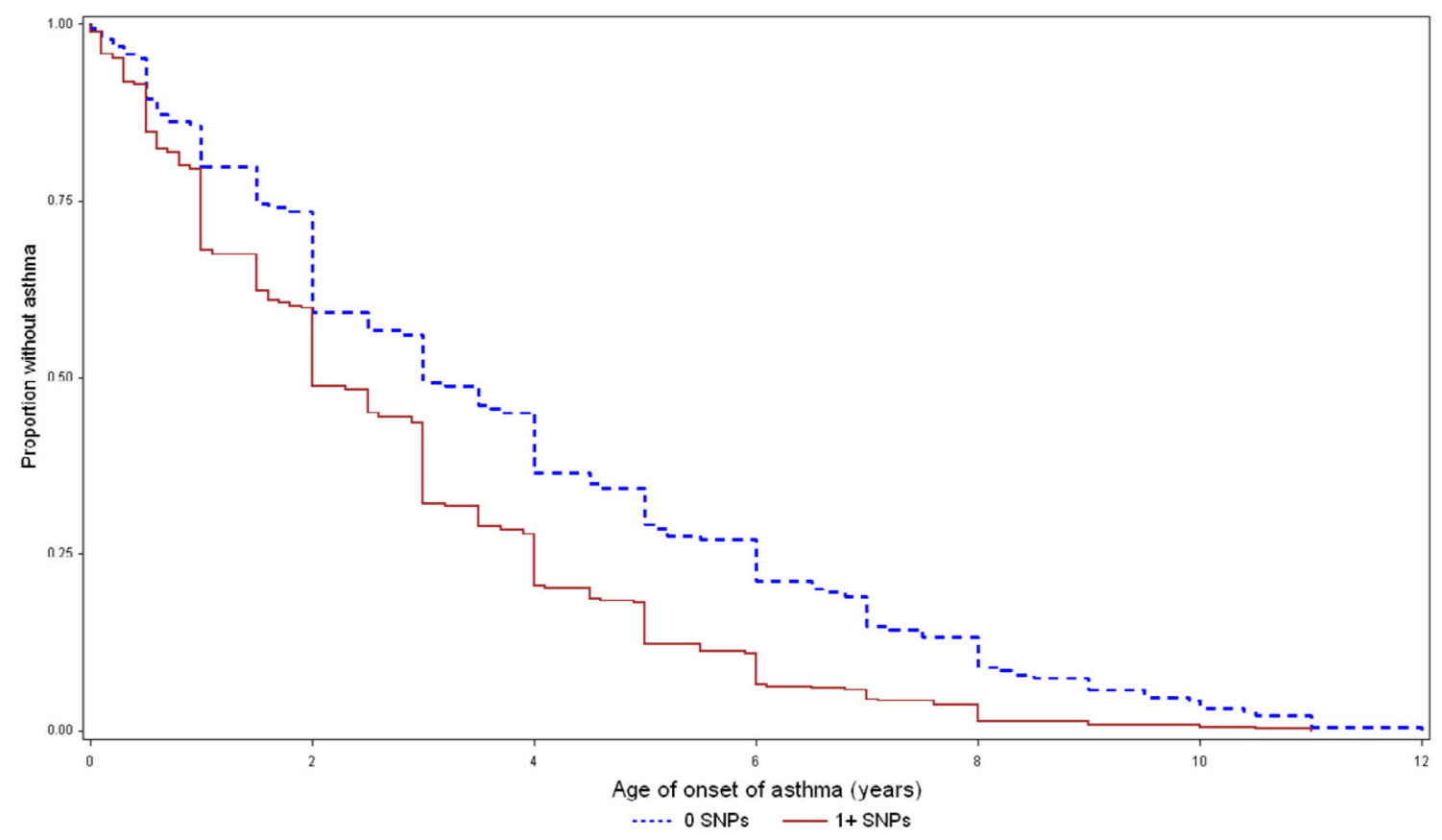

Figure 3. Age of onset and asthma phenotypes by presence of any the two earlier onset SNPs (rs9815663 and rs7927044)

Top: Time to onset of asthma in CAMP. Blue/dashed line: Children with none of the earlier onset SNPs. Red/continuous: Children with $\geq 1$ of the SNPs. Middle: FEV 1 during 4 years of follow-up in CAMP. Bottom: Albuterol use score during 4 years of follow-up in CAMP. 

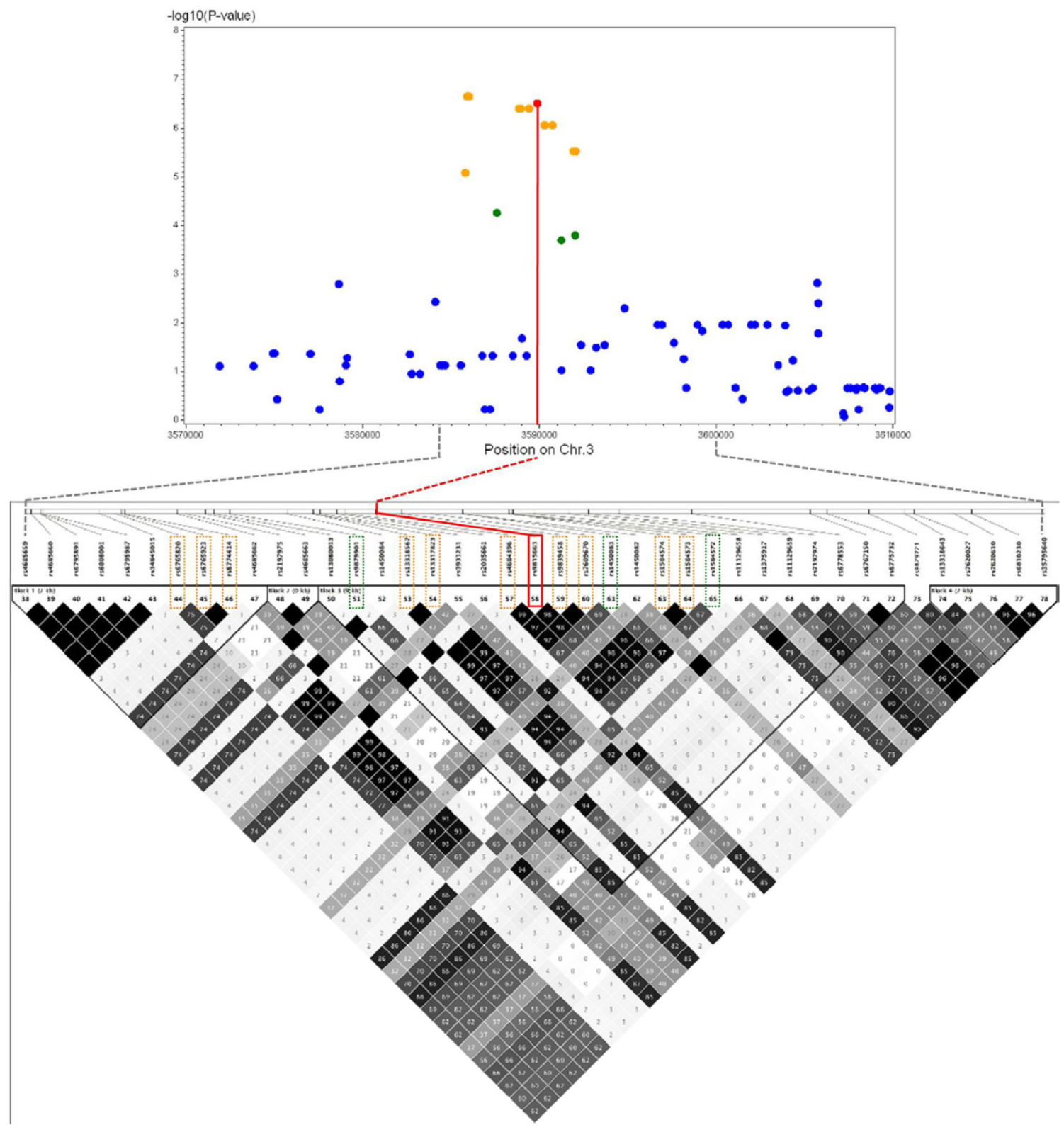

Figure 4. LD plot from CAMP for SNP rs9815663 and - $\log 10$ P-values for associated SNPs LD plot for SNP rs9815663 (+/-30Kb) shown (bottom), with -log10(P-values) for association with age of onset of asthma in CAMP (top). Red=rs9815663. Orange $=10$ SNPs in high LD $\left(r^{2}>0.75\right)$. Green $=3$ SNPs in moderate LD $\left(r^{2}>0.50\right)$. 
Table 1

Main characteristics of study participants

\begin{tabular}{|c|c|c|c|c|}
\hline & CAMP & GACRS & BAMSE $^{\dagger}$ & PACT \\
\hline Country of origin & US and Canada & Costa Rica & Sweden & U.S. \\
\hline \multirow[t]{2}{*}{$\mathrm{N}$} & $573^{t^{t}}$ & 591 & 107 & 233 \\
\hline & \multicolumn{4}{|c|}{ Number of subjects (\%) } \\
\hline Male gender & $338(59.5 \%)$ & $351(59.3 \%)$ & $69(64.5 \%)$ & $147(63.1 \%)$ \\
\hline \multirow[t]{2}{*}{ ETS } & $203(35.9 \%)$ & $181(30.7 \%)^{*}$ & $27(26.2 \%)^{*}$ & $103(44.6 \%)^{*}$ \\
\hline & \multicolumn{4}{|c|}{ Mean (SD) } \\
\hline Age at enrollment (yrs) & $8.9(2.1)$ & $9.0(1.8)$ & Birth * & $9.9(2.2)^{*}$ \\
\hline Age of onset & $3.1(2.5)$ & $2.5(2.3)^{*}$ & $3.1(2.4)$ & $3.3(2.7)$ \\
\hline $\mathrm{FEV}_{1}(\%$ predicted $)$ & $93.9 \%(14.1)$ & $99.7 \%(17.1)^{*}$ & $104.8 \%(11.8)^{*}$ & $99.1 \%(12.0)^{*}$ \\
\hline \multirow[t]{2}{*}{$\mathrm{FEV}_{1} / \mathrm{FVC}(\%)$} & $79.7 \%(8.4)$ & $82.5 \%(7.4)^{*}$ & $84.1 \%(6.6)^{*}$ & $80.2 \%(7.3)$ \\
\hline & \multicolumn{4}{|c|}{ Median (IQR) } \\
\hline Total IgE (IU/mL) $)^{\xi}$ & $433(173-639)$ & $391(114-932)^{*}$ & $\mathrm{n} / \mathrm{a}$ & $173(60-390)^{*}$ \\
\hline Eosinophils $\left(\text { cells } / \mathrm{mm}^{3}\right)^{\xi}$ & $400(200-639)$ & $520(270-790)^{*}$ & $\mathrm{n} / \mathrm{a}$ & $336(200-632)$ \\
\hline
\end{tabular}

ETS=Environmental tobacco smoke exposure.

p $<0.05$ for the comparison between each cohort and CAMP.

In BAMSE, pulmonary function data was available in 90/107 (84\%) children; total IgE and eosinophils not available.

${ }_{170}$ in the budesonide treatment arm, and 403 in the nedocromil/placebo arm.

$\S_{\text {Analyzed as } \log 10}$

$\mathrm{n} / \mathrm{a}=$ data not available 


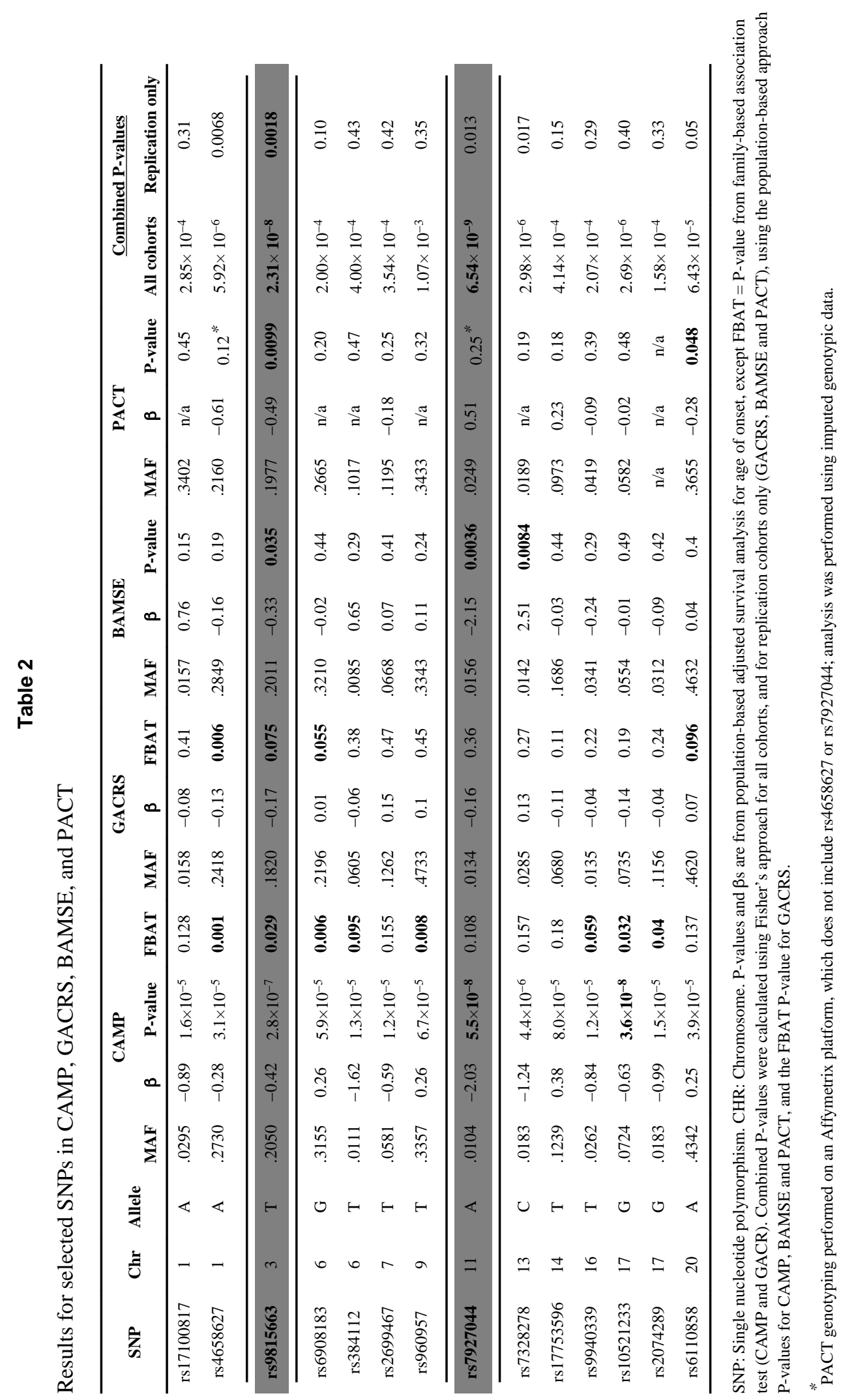


Table 3

Age of onset of asthma and asthma phenotypes in CAMP, by genotype.

\begin{tabular}{ccccc}
\hline Number of (+)SNPs & $\mathbf{N}(\%)$ & Mean age of onset, yrs & Mean $_{\mathbf{F E V}}, \boldsymbol{\%}$ of predicted & Mean albuterol use score $^{\star}$ \\
\hline 0 & $201(35.1)$ & $\mathbf{3 . 4}(2.57)$ & $\mathbf{9 4 . 5 \% ( 1 4 . 3 )}$ & $\mathbf{1 . 8 6}(1.33)$ \\
21 & $372(64.9)$ & $\mathbf{2 . 5}(2.13)^{*}$ & $\mathbf{9 3 . 7 \% ( 1 3 . 9 ) *}$ & $\mathbf{2 . 1 1}(1.27) *$ \\
\hline
\end{tabular}

Age of onset, lung function, and medication use in genotyped children from CAMP ( $\mathrm{n}=573$ ), for children with 0 vs any risk alleles of the two "earlier onset" SNPs identified (rs9815663 and rs7927044). Numbers in parenthesis are standard deviations unless otherwise stated.

P $<0.01$ (0 vs $\geq 1$ SNPs) from adjusted longitudinal model.

${ }^{t} \mathrm{FEV}_{1}$ at the end of CAMP (month 48 of follow-up).

${ }^{*}$ Albuterol use score at the end of CAMP. Score (0-4): $0=$ none, $1=$ less than once a week, $2=$ at least once a week, $3=$ at least twice a week, $4=$ daily. 
Table 4

Longitudinal analysis for $\mathrm{FEV}_{1}(\%$ pred) and C1orf100 expression levels in CAMP

\begin{tabular}{l|c|c}
\hline & Model 1 & Model 2 \\
\hline Intercept $^{\dagger}$ & $96.1 \%(2.9)$ & $96.2 \%(2.9)$ \\
Clorf100 $^{*}$ & $-0.36 \%(0.08)^{* *}$ & $-0.44 \%(0.09)^{* *}$ \\
Budesonide $^{*}$ & $3.63 \%(1.6)^{*}$ & $3.23 \%(1.6)^{*}$ \\
Clorf100 $^{*}$ budesonide// & -- & $0.32 \%(0.16)^{*}$ \\
\hline
\end{tabular}

Models from adjusted longitudinal analysis for percent-predicted FEV 1 . Model 1 shows main effects of C1orf100 expression level and treatment with inhaled budesonide. Model 2 also includes the interaction term. Numbers represent $\beta$ coefficients from mixed-effects regression models with standard errors in parentheses.

$\mathrm{P}<0.05$,

**

$\mathrm{P}<0.001$.

${ }^{\dagger}$ Children in CAMP with the lowest levels of C1orf100 and no budesonide treatment had $\mathrm{FEV}_{1} \sim 96.2 \%$.

${ }^{*}$ Clorf100 gene expression levels as log-intensity values. There was a drop of $\sim 0.4 \%$ in $\mathrm{FEV}_{1}$ for each log increase in $C 10$ orf 100 level.

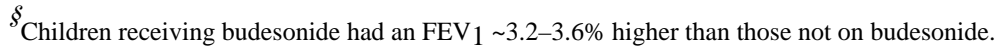

/Children with higher C1orf100 levels had a greater response to budesonide: for each log increase in the level, treatment improved their FEV 1 by $\sim 0.3 \%$ more than those with lower expression levels of the gene.

In summary, higher expression levels of $C 10 r f 100$ were associated with lower $\mathrm{FEV}_{1}$; budesonide improved $\mathrm{FEV}_{1}$ and also partially reversed the reduction in FEV1 associated with higher C1orf100 levels. 